\title{
The Influence of Staffing Characteristics on Quality of Care in Nursing Homes
}

\author{
Nicholas G. Castle and John Engberg
}

Objective. The influence staffing levels, turnover, worker stability, and agency staff had on quality of care in nursing homes was examined.

Data Sources/Study Setting. Staffing characteristics came from a survey of nursing homes $(N=1,071)$ conducted in 2003. The staffing characteristics were collected for Nurse Aides, Licensed Practical Nurses, and Registered Nurses. Fourteen quality indicators came from the Nursing Home Compare website report card and nursing home organizational characteristics came from the Online Survey, Certification, and Recording system.

Study Design. One index of quality (the outcome) was created by combining the 14 quality indicators using exploratory factor analysis. We used regression analyses to assess the effect of the four staffing characteristics for each of the three types of nursing staff on this quality index in addition to individual analyses for each of the 14 quality indicators. The effect of organizational characteristics as well as the markets in which they operated on outcomes was examined. We examined a number of different model specifications.

Principal Findings. Quality of care was influenced, to some degree, by all of these staffing characteristics. However, the estimated interaction effects indicated that achieving higher quality was dependent on having more than one favorable staffing characteristic - the effect of quality was larger than the sum of the independent effects of each favorable staffing characteristic.

Conclusions. Our results indicate that staff characteristics such as turnover, staffing levels, worker stability, and agency staff should be addressed simultaneously to improve the quality of nursing homes.

Key Words. Nursing homes, quality, staffing

In recent years, workforce characteristics have become ever more salient issues in the long-term care industry (Stone 2004). Policy makers and researchers alike, recognize that caregivers in long-term care are an essential linchpin in helping provide quality care. For example, a number of states have mandated minimum staffing levels for nursing homes (Harrington 2005; Mueller 
et al. 2006). The Centers for Medicare and Medicaid Services (CMS) have funded a number of demonstrations to improve working conditions for the direct service community workforce (www.whitehouse.gov/news/ freedominitiative/freedominitiative.html).

It is possible that much can be learned from examining the effect of workforce characteristics in nursing homes, given the almost intransigent poor quality seen in many of these facilities (Institute of Medicine 2001). Although past research in this area has examined the effect of turnover (Castle and Engberg 2005) and staffing levels (Harrington and Swan 2003) on quality, there have been very few studies that have examined the impact of multiple workforce characteristics, or that have looked at whether different characteristics of the workforce interact to produce either high or low quality. Thus, prior underspecified models may have served to limit somewhat our understanding of which workforce characteristics influence most (least) quality of care. In this research, we examine the influence that multiple staffing characteristics, specifically staffing levels, turnover, worker stability, and agency staff, has on quality of care in a large sample of nursing homes.

\section{CONCEPTUAL MODEL AND HyPOTHESES}

Knapp and Missiakoulis (1983) and Staw (1980) have both reviewed the implications of workforce characteristics on quality of care. Although these two reviews did not specifically examine long-term care issues it is likely that their findings can be extended to nursing homes. Thus, we propose workforce characteristics are likely to influence resident care through at least six mechanisms; workforce characteristics can: (1) be expensive for the facility, therefore diverting dollars from care; (2) interfere with continuity of care; (3) increase the number of inexperienced workers; (4) weaken standards of care; (5) cause psychological distress for some residents; and (6) increase the work load for remaining staff.

Based on these six mechanisms, we propose that the staffing characteristics we examine (staffing levels, turnover, worker stability, and agency staff) will likely be associated with quality. In addition, we believe that market

Address correspondence to Nicholas G. Castle, Ph.D., A649 Crabtree Hall, Graduate School of Public Health, 130 DeSoto Street, Pittsburgh, PA 15261.John Engberg, Ph.D., Senior Economist, is with RAND, Pittsburgh, PA. 
Figure 1: Conceptual Model.

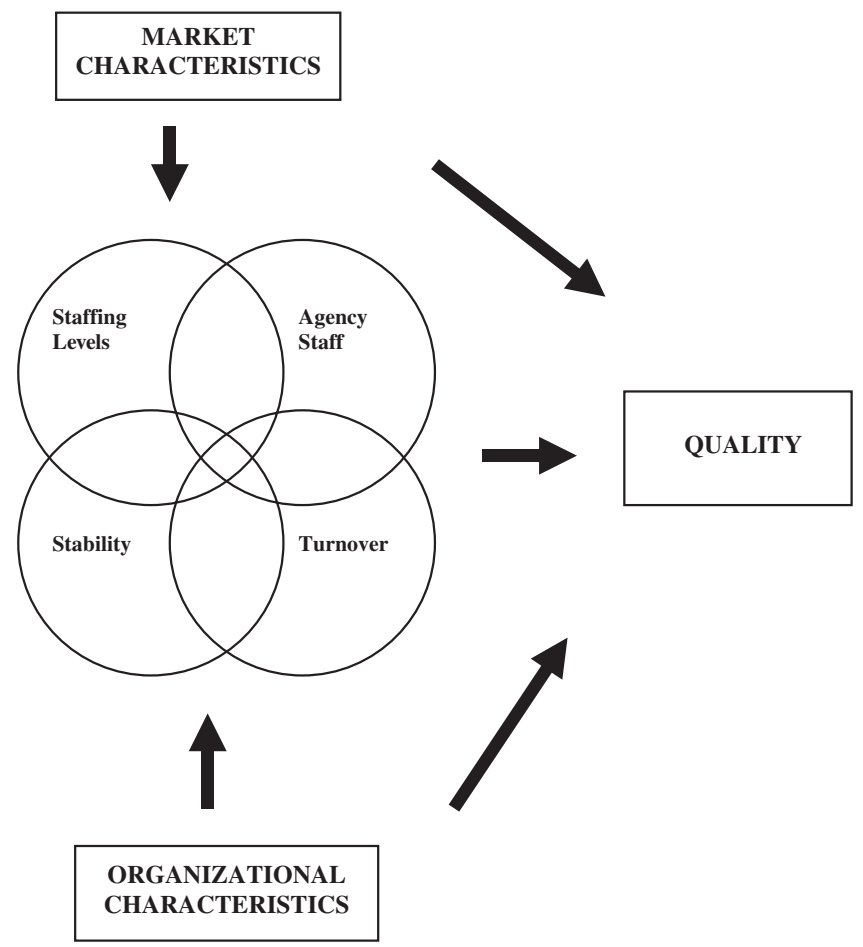

characteristics and organizational characteristics are also related to quality of care as they have shown an extremely robust association with quality of care in prior nursing home studies (e.g., Harrington and Swan 2003). This conceptual model is presented as Figure 1. Using this conceptual framework, and findings from prior literature, we now indicate how these staffing characteristics are likely to affect the quality of care.

\section{Staffing Levels}

Associations between nurse staffing and quality in acute settings are well documented (e.g., Needleman et al. 2001). Staffing levels in nursing homes have been examined less, but have recently drawn substantially increased attention (e.g., Konetzka et al. 2004). Staffing levels in Medicare/Medicaid certified nursing homes are mandated through federal government regulations, which 
"require that a facility provide services by a sufficient number of nursing personnel on a 24-hour basis to provide the required care in accordance with care plans." In addition, 37 states mandate specific staffing levels (CMS 2002).

Some recent work has demonstrated a positive association between nursing home nurse staffing levels and quality. A study of 43 nursing homes in 16 states found low Nurse Aide (NA) staffing levels were positively associated with resident weight loss, and low NA and Registered Nurse (RN) levels were positively associated with the rate of ungroomed residents (Health Care Financing Administration [HCFA] 2000). Harrington and Swan (2003) identified staffing to be associated with the activities of daily living (ADL) dependency of residents. Based on these studies, we hypothesize (H1) that: lower staffing levels will be associated with lower quality.

\section{Staff Turnover}

The high rate of caregiver turnover in nursing homes is a perennial issue of concern, spanning at least the past 30 years (see Castle 2006 for a review). Turnover of NAs would appear to be especially high. Recent studies cite average annual NA turnover rates to be more than 100 percent in many facilities (Decker et al. 2003).

For the most part, studies examining the relationship between turnover and quality have had equivocal findings. Spector and Takada (1991), for example, found an association between high $\mathrm{RN}$ turnover and lower functional improvement of residents, but no association for death rates or functional decline. More recently, Castle and Engberg (2005) found consistently significant findings between NA plus Licensed Practical Nurse (LPN) turnover and quality, and between RN turnover and quality. Based on this recent research we also hypothesize $(\mathbf{H} 2)$ that: higher staff turnover will be associated with lower quality.

\section{Staff Stability}

Caregivers with long tenure in a nursing home, because of their experience, are able to pass along to newer staff essential work habits and protocols. These long-tenure staff tend to anchor the work flow, and are part of the institutional memory regarding how work is conducted at the facility. It is important to note that stability and turnover measure different constructs. For example, a high turnover rate relative to the stability rate may indicate that an organization is either having difficulty filling vacancies or has made several incorrect hiring decisions (Williams and Katz 1999). Research on stability is very limited. 
In nursing homes with high stability $(n=156)$, Barry, Brannon, and Mor (2005) identified low-pressure ulcer incidence. Bowers, Esmond, and Jacobson (2000) also suggest stability and quality are associated. We hypothesize (H3) that: lower staff stability levels will be associated with lower quality.

\section{Agency Staff}

Agency staff are temporary caregivers used by nursing homes to fill positions. These caregivers (including NAs, LPNs, and RNs) are most often provided by staffing agencies. In the hospital setting, high levels of similar staff (in this case the term "temps" or "contract staff" are also used) have been shown to be associated with low quality (Strzalka and Havens 1996). No empirical studies to date have examined the use of agency staff in nursing homes. However, a report to Congress cautioned that use of these staff may lower quality of care (Louwe and Kramer 2002). This report echoes anecdotal accounts in longterm care circles that agency staff are generally used by the worst performing facilities (e.g., Deitzer et al. 1992). Based on this, we hypothesize (H4) that: higher agency staffing levels will be associated with lower quality.

\section{Staffing Characteristic Interactions}

As noted above, few studies have examined the impact of multiple staffing characteristics on quality of care in nursing homes. Indeed, we could only identify one study by Harrington and Swan (2003) that used both staffing levels and turnover in examining quality outcomes and a further study by Barry, Brannon, and Mor (2005) that examined the impact of both turnover and stability on quality outcomes. Harrington and Swan (2003) note that staffing levels and turnover may be endogenous. That is, high staff turnover can lower staffing levels, but the reverse may also occur. Nevertheless, underspecified models may have served to limit somewhat our understanding of the relationship between staffing characteristics and quality of care.

Given our conceptual model (see Figure 1), and the six mechanisms (listed previously) with which staffing levels, turnover, worker stability, and agency staff could influence quality, we believe that interaction effects are likely. For example, low staffing will increase workloads for all staff and high turnover will decrease experience levels. Thus low staffing levels and high turnover are likely to lower quality more than either alone. We hypothesize (H5) that: interaction effects will exist for the associations between turnover, staffing levels, worker stability, and agency staff and quality. 


\section{DATA AND METHODS}

\section{Source of Data}

Data used in this investigation came from four sources: first, from a survey of nursing home administrators conducted during March-June 2003; second, from the 2003 Nursing Home Compare (NHC); third, from the 2004 Online Survey, Certification, and Recording (OSCAR) data; and fourth, from the 2005 Area Resource File (ARF). The information regarding staffing characteristics came from the administrator survey, quality indicators came from $\mathrm{NHC}$, characteristics of the nursing home came from the OSCAR, and characteristics of the market came from the ARF.

Nursing Home Administrator Survey. We conducted a survey of nursing home administrators in order to get reliable information on staffing. We undertook this primary data collection because this information is either not found in commonly used secondary sources of nursing home information, or is not considered to be reliable if reported in secondary sources such as OSCAR (Straker 1999).

The data were collected as part of an initiative to examine caregiver turnover. We first determined the average caregiver turnover rates in each state (using 2002 data from the American Health Care Association [AHCA]; Decker et al. 2003) and then we categorized the states into terciles depending on the aggregate caregiver turnover rates. We randomly selected two states from each tercile, and then used a random sample of facilities within each selected state. The two high caregiver turnover states included in this investigation are Missouri (MO) and Texas (TX); the two medium caregiver turnover states are Pennsylvania (PA) and New York (NY); and, the two low caregiver turnover states are Connecticut $(\mathrm{CT})$ and New Jersey (NJ). For example, TX facilities had an average of 233 percent combined NA, LPN, and RN turnover; PA facilities had an average of 131 percent combined turnover; and CT facilities had an average of 116 percent combined turnover.

The facility sample consisted of a random sample of 40 percent $(n=1,540)$ of facilities chosen from each state's pool of eligible facilities. Eligible facilities were defined as nursing homes participating in Medicare and/ or Medicaid certification. We used this eligibility definition because these are the facilities included in the OSCAR data, which were used, first, to identify facilities in each state, and second, to identify the mailing address for each facility. Eligible facilities included 547 nursing homes from MO, 1,127 from TX, 749 from PA, 662 from NY, 253 from CT, and 352 from NJ (total $N=3,690$ ). 
OSCAR. The OSCAR data come from the Medicare and/or Medicaid certification process conducted by state licensure and certification agencies on a yearly basis. These data include most (97 percent) facilities in the United States. In 2003 approximately 17,000 facilities were included in the data, including all of the facilities used in this analysis. Many data elements, especially organizational characteristics, are considered reliable (Harrington et al. 2003). In this study, we take information on the following organizational characteristics from OSCAR: bed size, ownership, chain membership, occupancy, and Medicaid occupancy.

$N H C$. We recognize that many quality indicators could be used for these analyses. These could come from secondary data sources such as the Minimum Data Set (MDS) or the OSCAR data. In this research, we chose to use the Quality Measures (QMs) reported on NHC (www.Medicare.gov/ NHCompare). NHC is a web-based report card providing information for all Medicare and/or Medicaid certified nursing homes. The QMs reported were subject to extensive testing, are derived from the MDS, are readily available online, and represent measures relevant to both consumers and providers (General Accounting Office [GAO] 2002). A formal validation study also concluded that the measures were reliable and valid (Abt Associates 2003). For these reasons the QMs from NHC were used in this analysis.

Fourteen QMs (presented in Table 1) in NHC are used in this analysis. The development of these measures is described in a GAO report (GAO 2002) and precise specifications are given in a technical report (Abt Associates 2004). Eleven measures are for long-stay residents (defined as those with quarterly MDS assessments) and three measures are for short-stay residents (defined as those with 14-day MDS assessments).

$A R F$. ARF data are compiled from a number of data sources, including the American Hospital Association annual hospital survey, the U.S. Census of Population and Housing, the Centers for Disease Control, and the National Center for Health Statistics. These data are aggregated at the county level. Extensive details regarding these data can be found on the World Wide Web (http:// wonder.cdc.gov/wonder/sci_data/census/arf). We use these data to examine the level of nursing home competition and unemployment rates in each county.

\section{Model Specification and Operationalization}

The outcomes of interest are the 14 QMs. The distributions of these measures were skewed, with few facilities having high values, which would be 


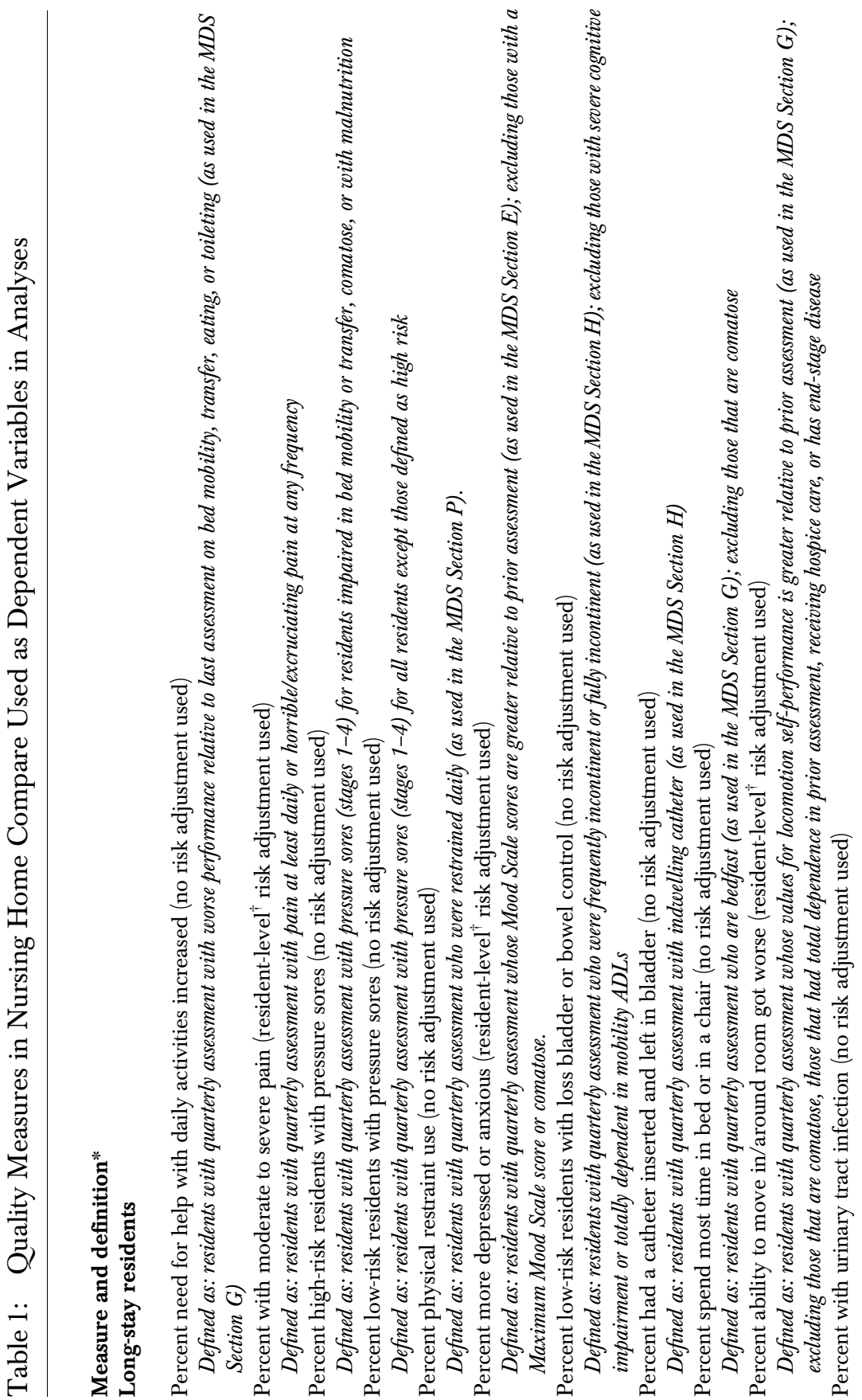




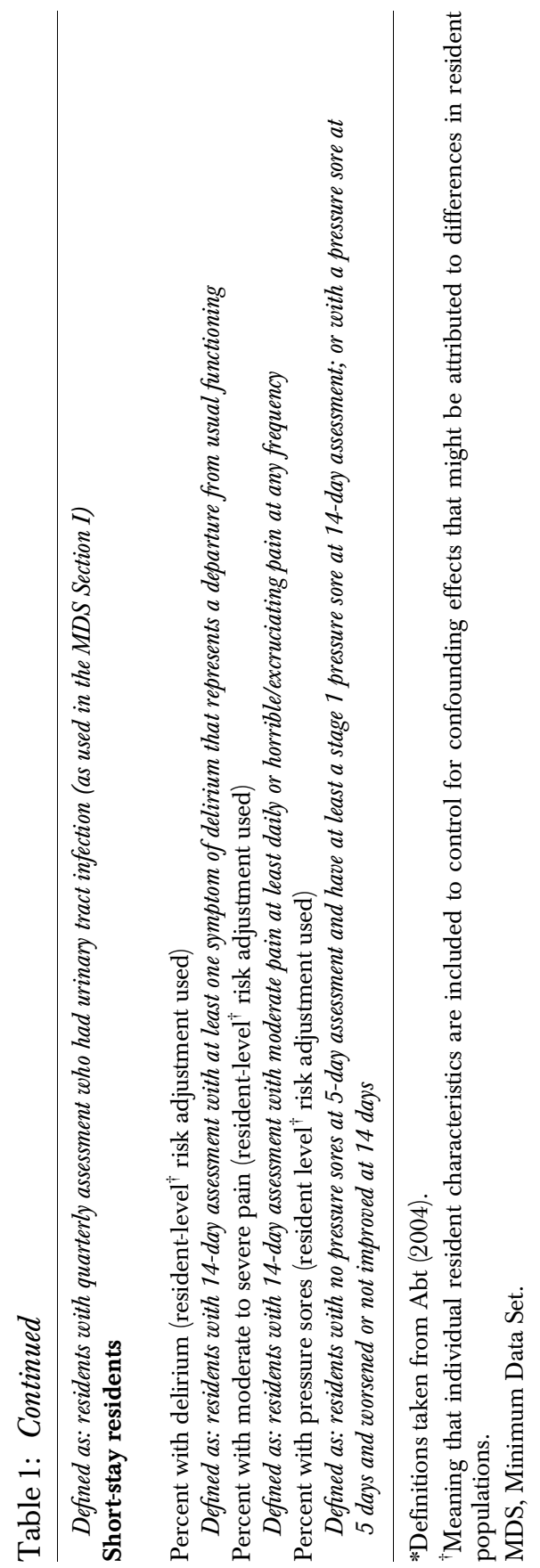


an indicator of lower quality. Thus, we transformed all the QMs to create more normally distributed outcomes. For each measure, we took the natural logarithm after adding to lowest positive value to all observations to avoid taking the logarithm of zero. This has the advantage of allowing differences in the transformed QMs to be interpreted as percent changes in quality and permits the QMs to be combined through exploratory factor analysis (EFA), as described below.

The EFA examined whether the QMs could be combined into a smaller number of measures that adequately summarized the information of the 14 measures. We estimated principal factors and retained all factors with eigenvalues greater than one. A single factor resulting from the long-stay QMs was most robust, and was used as the dependent variable in the regression analysis.

Our independent variables of interest are NA, LPN, and RN staffing levels, turnover rates, stability, and agency use rates. For staffing levels, we include full-time-equivalent (FTE) staff per 100 residents for NAs, LPNs, and RNs. This includes full-time and part-time workers (but not agency staff). Turnover is defined as the sum of terminations for 6 months divided by sum of established positions. This was collected by the number of FTE staff and multiplied by two, to give an annual rate. This turnover rate included staff on all shifts, part-time staff, and voluntary turnover. As a measure of stability we use the percent of NAs, LPNs, and RNs that had worked for the facility 5 years or more. As a measure of use of agency staff, we use the percent of NA, LPN, and $\mathrm{RN}$ positions filled by agency staff. We then took the natural logarithm of each of these values (after shifting to remove zeros), in order to reduce the skewness of the distributions. Further details of these and other variables used in the analyses are given in Table 2.

We know from other nursing home studies that organizational characteristics (in addition to staffing characteristics) have a strong impact on quality indicators. Therefore, size, ownership, chain membership, overall occupancy, and Medicaid occupancy are included as organizational level variables (Spector and Takada 1991; Grabowski 2001). Likewise, market characteristics can influence quality indicators. We include market competition from other nursing homes (Castle and Engberg 2005). State dummy variables are also included in the analyses. However, we do not include the severity of physical illnesses among residents (i.e., risk adjustment). This is because the NHC QMs are already either risk adjusted, or were recommended to be used without further risk adjustment (GAO 2002); and, in sensitivity analyses risk adjustment did not influence any of the findings. 


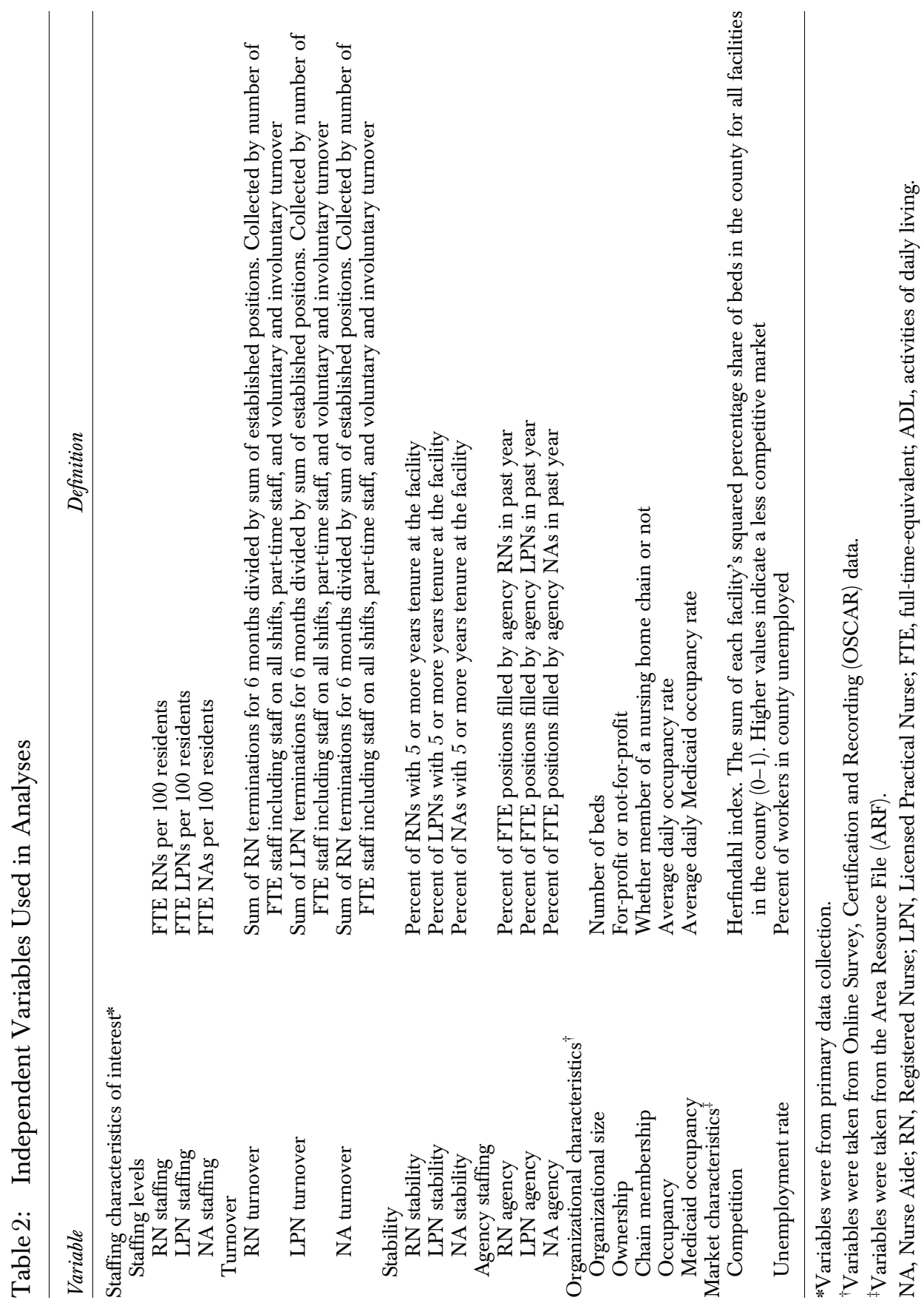


Analyses

We examined the level of collinearity among the independent variables, and multicollinearity using the variance inflation factor (VIF) test. We were especially concerned with the potential correlation between the staffing level variables, but the correlation between these variables was low (i.e., $r \leq 0.62$ ).

We combined the QMs to form an index of quality. We created this index using EFA after transforming the QMs to be more normally distributed. Using the 11 long-stay QMs, we identified the first principal factor had an eigenvalue of 3.87, whereas, the second had an eigenvalue of 0.49 , suggesting that this factor captured much of the variation of these QMs.

Our main interest is on the effect of the four characteristics of each of the three types of nursing staff on quality of care, so we include these 12 variables in each of the regressions. We also include eight other characteristics of the facilities and the markets in which they operate. Our first specification includes only these two sets of terms.

Although this specification captures the main effect of the staffing characteristics on the QMs, it is likely that the effect of each of the staffing characteristics depends on the level of that characteristic or of the other characteristics. Therefore, we created a set of squared terms and interactions to capture this variation in effect. The squared terms capture nonlinear relationships between staffing characteristics and quality. The interactions allow us to examine whether the effect of a particular staffing characteristic on quality is influenced by the level of a different staffing characteristic. For example, the coefficient on the interaction between NA agency use and NA stability would estimate whether the effect of NA agency use on quality differed between facilities with a stable NA workforce and those with an unstable NA workforce.

In order to aid interpretation of the squared and interaction terms, we subtracted out the mean of each staffing characteristic variable before creating the squared and interaction terms. This allows the coefficients on the linear staffing characteristic terms to be interpreted as the effect of the staffing characteristic on quality at the mean value of the staffing characteristic. A positive (negative) coefficient on a squared term implies that the effect of the characteristic is more positive (negative) at values of the staffing characteristic greater than the mean. A positive (negative) coefficient on an interaction implies that the effect of one of the characteristics is more positive (negative) at values of the other staffing characteristic above the mean. To facilitate 
interpretation of these nonlinearities and interactions, we provide graphs of the estimated impact of staffing characteristics on quality.

We have two specifications that use these squared and interaction terms. In one, we include all the squared terms and interactions. The other is a compromise between the parsimony of the first specification that includes only the main effects and the inclusiveness of the specification that includes all the squared and interaction terms. We run stepwise regressions in which the 12 linear staffing characteristic measures and the eight organizational and market characteristics are forced into the regression but the squared and interaction staffing terms only are retained if they have a $p$-value $<.20$. This specification permits a more convenient interpretation of the results with the least inclusive specification, but must be checked against the most inclusive specification to prevent bias from the omission of important explanatory variables.

The analysis of the quality factor uses least squares regression because the dependent variable is a principal factor of transformed QMs, designed to be approximately normally distributed. Standard errors are estimated using a Huber-White sandwich estimator that accounts for unmodeled correlation of quality within counties.

The individual QMs were also examined using the same model specifications described above. However, in these analyses we determined that the QMs were highly skewed. We accounted for this skew by using negative binomial regression models, which is a generalization of the Poisson regression model for count data that permits for overdispersion that is evidenced by the large number of facilities with 0 values. This method also incorporates the sandwich estimator for robust standard errors. The coefficients are reported in incident-rate ratio form, which is similar to odds ratios in that estimates $>1$ represent a positive association between the explanatory variable and the outcome. Note, however, that high values of the QMs are indicators of lower quality because they indicate a high percentage of residents with the specified negative outcome.

\section{RESULTS}

One thousand and seventy-one responses were received from our nursing home sample (response rate $=70$ percent). The response rate varied little across the states, and in general most items on the questionnaire were answered. Missing data occurred in $<1$ percent of cases and were evenly distributed across questions and states. 
Table 3 presents descriptive statistics for the variables used in the analysis. Staffing levels were 14.7, 16.6, and 33.4 FTEs per 100 residents for RNs, LPNs, and NAs, respectively. The average voluntary annual RN, LPN, and NA turnover rates were $30.6,31.6$, and 54.7 percent, respectively. Average 5 -year stability rates were $16.5,30.4$, and 14.9 percent for RNs, LPNs, and NAs, respectively. Agency use averaged 7.7, 1.9, and 20.2 percent for RNs, LPNs, and NAs, respectively. These staffing characteristics were not highly correlated, the highest correlation $(-0.62)$ was found between NA staffing and turnover (not shown).

Table 4 presents the coefficient estimates for the regressions of the quality factor from the EFA. Standard errors, adjusted for clustering within market, are in parentheses below the coefficient estimates. We first examine the main effects as estimated by the stepwise regression in the third column, which can be interpreted as the association of each staffing characteristic with quality when all staffing characteristics are at their average values. For staffing levels, we find that high $\mathrm{RN}$ levels are associated with higher overall quality $(p<.01)$; whereas, a high number of LPNs are associated with lower overall quality $(p<.05)$, and NA staffing levels were not significant (thus we find mixed support for $\mathrm{H} 1$ ). For turnover, we find that high $\mathrm{RN}$ turnover is associated with higher overall quality $(p<.05)$, but the LPN and NA turnover variables are not significant (thus we find no support for H2). For stability, we find that high rates of $\mathrm{RN}$ stability are associated with lower overall quality $(p<.10)$ and high rates of NA stability are associated with higher overall quality $(p<.05$; thus we find mixed support for H3). For agency use, we find that high rates of $\mathrm{RN}$ agency use are associated with lower quality $(p<.01)$ and that high rates of NA agency use are associated with lower quality $(p<.01)$; whereas, high rates of LPN agency use are associated with higher quality $(p<.05$; thus we find mixed support for $\mathrm{H} 4)$.

The interactions between turnover and stability for NAs and for RNs are the only interactions that are significant in the stepwise regression and in the full specification (as shown in the second column of Table 4) that uses this factor as the dependent variable (thus we found weak support for H5). The interaction is positive for NAs but negative for RNs. As can be seen in Figure 2, there is little association between NA agency use and the quality factor for high levels of turnover. However, at low levels of turnover, the association between agency use and the quality factor is negative. Figure 3 shows that the negative coefficient on the interaction of RN agency use and turnover implies the opposite situation; the association between $\mathrm{RN}$ agency use and quality is negative for high levels of turnover, but positive for low levels of turnover. 
Table 3: Descriptive Statistics of Quality Indicators, Staffing Characteristics, and Control Variables*

\begin{tabular}{|c|c|c|}
\hline & $\begin{array}{l}\text { Mean } \\
\text { (or \%) }\end{array}$ & $\begin{array}{l}\text { Standard } \\
\text { Deviation }\end{array}$ \\
\hline \multicolumn{3}{|l|}{ Quality indicators ${ }^{\dagger}$} \\
\hline Percent need for help with daily activities increased & 19.4 & $(12.6)$ \\
\hline Percent with moderate to severe pain & 5.1 & $(3.4)$ \\
\hline Percent high-risk residents with pressure sores & 13.4 & $(8.6)$ \\
\hline Percent low-risk residents with pressure sores & 4.4 & $(5.2)$ \\
\hline Percent physical restraint use & 5.2 & $(5.1)$ \\
\hline Percent more depressed or anxious & 14.3 & $(17.3)$ \\
\hline Percent low-risk residents with loss bladder or bowel control & 47.7 & $(17.2)$ \\
\hline Percent had a catheter inserted and left in bladder & 6.5 & $(7.3)$ \\
\hline Percent spend most time in bed or in a chair & 3.9 & $(5.0)$ \\
\hline Percent ability to move in/around room got worse & 12.8 & $(7.7)$ \\
\hline Percent with urinary tract infection & 8.0 & $(5.2)$ \\
\hline Percent with delirium & 3.1 & $(4.4)$ \\
\hline Percent with moderate to severe pain & 21.8 & (8.9) \\
\hline Percent with pressure sores & 17.3 & (8.9) \\
\hline \multicolumn{3}{|l|}{ Staffing characteristics of interest } \\
\hline RN staffing & 14.7 & $(9.3)$ \\
\hline LPN staffing & 16.6 & $(8.1)$ \\
\hline NA staffing & 33.4 & $(10.1)$ \\
\hline $\mathrm{RN}$ turnover & $30.6 \%$ & $(36.7)$ \\
\hline LPN turnover & $31.6 \%$ & $(41.9)$ \\
\hline NA turnover & $54.7 \%$ & $(79.3)$ \\
\hline RN stability & $16.5 \%$ & $(13.0)$ \\
\hline LPN stability & $30.4 \%$ & $(16.4)$ \\
\hline NA stability & $14.9 \%$ & $(7.5)$ \\
\hline $\mathrm{RN}$ agency & $7.7 \%$ & $(12.7)$ \\
\hline LPN agency & $1.9 \%$ & $(3.9)$ \\
\hline NA agency & $20.2 \%$ & $(18.9)$ \\
\hline \multicolumn{3}{|l|}{ Organizational characteristics ${ }^{\ddagger}$} \\
\hline Bed size & 131 & (93) \\
\hline For-profit & $55 \%$ & $(-)$ \\
\hline Chain membership & $41 \%$ & $(-)$ \\
\hline Average occupancy & $86 \%$ & $(15)$ \\
\hline Average Medicaid occupancy & $54 \%$ & (23) \\
\hline \multicolumn{3}{|l|}{ Market characteristics ${ }^{\mathrm{s}}$} \\
\hline Competition (Herfindahl index) & 0.20 & 0.22 \\
\hline Unemployment rate & 4.2 & $(1.6)$ \\
\hline
\end{tabular}

*Statistics presented come from the analytic file consisting of 1,071 facilities and 563 markets;

These variables are not significantly different $(p>.05)$ than the national averages reported in Nursing Home Compare for 2004.

${ }^{\ddagger}$ These variables are not significantly different $(p>.05)$ than the national averages reported in Online Survey, Certification, and Recording (OSCAR) data for 2004.

${ }^{\S}$ These variables are not significantly different $(p>.05)$ than the national averages reported in the Area Resource File (ARF) data for 2004.

NA, Nurse Aide; RN, Registered Nurse; LPN, Licensed Practical Nurse; FTE, full-time-equivalent. 
Table 4: Regression Analyses Examining Staffing Characteristics and the Quality Factor ${ }^{\dagger}$

\begin{tabular}{|c|c|c|c|}
\hline & $\begin{array}{c}\text { Main Effects } \\
\text { Only }\end{array}$ & $\begin{array}{l}\text { All Nonlinear } \\
\text { Terms and } \\
\text { Interactions }\end{array}$ & $\begin{array}{c}\text { Stepwise (Including } \\
\text { Nonlinear Terms } \\
\text { and Interactions) }\end{array}$ \\
\hline Log RN staffing & $\begin{array}{l}0.635^{* * * * *} \\
(0.091)\end{array}$ & $\begin{array}{l}0.700 * * * * \\
(0.107)\end{array}$ & $\begin{array}{l}0.645^{* * * *} \\
(0.091)\end{array}$ \\
\hline Log LPN staffing & $\begin{array}{r}-0.161^{*} \\
(0.087)\end{array}$ & $\begin{array}{c}-0.205^{* * *} \\
(0.100)\end{array}$ & $\begin{array}{c}-0.175^{* * *} \\
(0.079)\end{array}$ \\
\hline Log NA staffing & $\begin{array}{r}-0.152 \\
(0.153)\end{array}$ & $\begin{array}{c}0.083 \\
(0.181)\end{array}$ & $\begin{array}{c}0.072 \\
(0.174)\end{array}$ \\
\hline Log RN turnover & $\begin{array}{l}0.191^{\text {****** }} \\
(0.038)\end{array}$ & $\begin{array}{l}0.149^{* * *} \\
(0.061)\end{array}$ & $\begin{array}{l}0.095^{* * *} \\
(0.041)\end{array}$ \\
\hline Log LPN turnover & $\begin{array}{r}-0.071 \\
(0.051)\end{array}$ & $\begin{array}{r}-0.077 \\
(0.056)\end{array}$ & $\begin{array}{r}-0.041 \\
(0.054)\end{array}$ \\
\hline Log NA turnover & $\begin{array}{c}-0.081 \\
(0.050)\end{array}$ & $\begin{array}{c}-0.023 \\
(0.049)\end{array}$ & $\begin{array}{r}-0.030 \\
(0.049)\end{array}$ \\
\hline Log RN stability & $\begin{array}{r}-0.028 \\
(0.048)\end{array}$ & $\begin{array}{r}-0.075 \\
(0.050)\end{array}$ & $\begin{array}{r}-0.081^{*} \\
(0.045)\end{array}$ \\
\hline Log LPN stability & $\begin{array}{c}0.105 \\
(0.079)\end{array}$ & $\begin{array}{r}-0.005 \\
(0.093)\end{array}$ & $\begin{array}{c}0.009 \\
(0.087)\end{array}$ \\
\hline Log NA stability & $\begin{array}{l}0.129^{* * * * *} \\
(0.046)\end{array}$ & $\begin{array}{l}0.148^{* * *} \\
(0.064)\end{array}$ & $\begin{array}{l}0.148^{* * *} \\
(0.058)\end{array}$ \\
\hline Log RN agency & $\begin{array}{c}-0.058^{* * * * *} \\
(0.018)\end{array}$ & $\begin{array}{c}-0.075^{* * * * *} \\
(0.022)\end{array}$ & $\begin{array}{c}-0.070^{* * * *} \\
(0.021)\end{array}$ \\
\hline Log LPN agency & $\begin{array}{c}0.039^{* * *} \\
(0.016)\end{array}$ & $\begin{array}{c}0.024 \\
(0.018)\end{array}$ & $\begin{array}{l}0.045^{* *} \\
(0.019)\end{array}$ \\
\hline Log NA agency & $\begin{array}{c}-0.230 * * * * \\
(0.029)\end{array}$ & $\begin{array}{c}-0.259^{* * * *} \\
(0.033)\end{array}$ & $\begin{array}{c}-0.271^{\text {***** }} \\
(0.030)\end{array}$ \\
\hline Average occupancy & $\begin{array}{c}-0.007 \\
(0.273)\end{array}$ & $\begin{array}{r}-0.036 \\
(0.261)\end{array}$ & $\begin{array}{c}-0.014 \\
(0.264)\end{array}$ \\
\hline Private pay occupancy & $\begin{array}{r}-0.373^{*} \\
(0.211)\end{array}$ & $\begin{array}{r}-0.377^{*} \\
(0.201)\end{array}$ & $\begin{array}{c}-0.411^{* *} \\
(0.207)\end{array}$ \\
\hline Bed size & $\begin{array}{c}-0.058^{* * * * *} \\
(0.022)\end{array}$ & $\begin{array}{c}-0.060^{* * * * *} \\
(0.022)\end{array}$ & $\begin{array}{c}-0.060^{* * * * *} \\
(0.022)\end{array}$ \\
\hline Special care unit & $\begin{array}{r}-0.068 \\
(0.073)\end{array}$ & $\begin{array}{r}-0.061 \\
(0.075)\end{array}$ & $\begin{array}{r}-0.056 \\
(0.072)\end{array}$ \\
\hline Chain member & $\begin{array}{c}0.051 \\
(0.052)\end{array}$ & $\begin{array}{c}0.078 \\
(0.053)\end{array}$ & $\begin{array}{c}0.076 \\
(0.052)\end{array}$ \\
\hline For-profit & $\begin{array}{r}-0.051 \\
(0.051)\end{array}$ & $\begin{array}{r}-0.069 \\
(0.053)\end{array}$ & $\begin{array}{r}-0.072 \\
(0.051)\end{array}$ \\
\hline Competition & $\begin{array}{r}-0.006 \\
(0.014)\end{array}$ & $\begin{array}{c}-0.004 \\
(0.014)\end{array}$ & $\begin{array}{c}-0.004 \\
(0.014)\end{array}$ \\
\hline Unemployment rate & $\begin{array}{r}-0.014 \\
(0.019)\end{array}$ & $\begin{array}{r}-0.017 \\
(0.017)\end{array}$ & $\begin{array}{r}-0.013 \\
(0.018)\end{array}$ \\
\hline Connecticut & $\begin{array}{c}-0.606^{* * * * *} \\
(0.133)\end{array}$ & $\begin{array}{c}-0.487^{\text {***** }} \\
(0.123)\end{array}$ & $\begin{array}{c}-0.433^{* * * * *} \\
(0.126)\end{array}$ \\
\hline Missouri & $\begin{array}{c}-0.463^{* * * * *} \\
(0.109)\end{array}$ & $\begin{array}{c}-0.438^{* * * * *} \\
(0.113)\end{array}$ & $\begin{array}{c}-0.359^{* * * *} \\
(0.113)\end{array}$ \\
\hline
\end{tabular}


Table 4: Continued

\begin{tabular}{|c|c|c|c|}
\hline & $\begin{array}{l}\text { Main Effects } \\
\text { Only }\end{array}$ & $\begin{array}{c}\text { All Nonlinear } \\
\text { Terms and } \\
\text { Interactions }\end{array}$ & $\begin{array}{c}\text { Stepwise (Including } \\
\text { Nonlinear Terms } \\
\text { and Interactions) }\end{array}$ \\
\hline New Jersey & $\begin{array}{c}-0.721^{* * * *} \\
(0.122)\end{array}$ & $\begin{array}{l}-0.728^{* * * *} \\
(0.140)\end{array}$ & $\begin{array}{l}-0.646^{* * * *} \\
(0.123)\end{array}$ \\
\hline New York & $\begin{array}{c}-0.265^{* * *} \\
(0.126)\end{array}$ & $\begin{array}{r}-0.176 \\
(0.155)\end{array}$ & $\begin{array}{r}-0.067 \\
(0.133)\end{array}$ \\
\hline Pennsylvania & $\begin{array}{r}-0.257^{*} \\
(0.134)\end{array}$ & $\begin{array}{r}-0.223 \\
(0.172)\end{array}$ & $\begin{array}{r}-0.107 \\
(0.142)\end{array}$ \\
\hline Log NA staffing squared & & $\begin{array}{c}0.623^{*} \\
(0.360)\end{array}$ & $\begin{array}{l}0.799^{* * *} \\
(0.327)\end{array}$ \\
\hline Log NA turnover squared & & $\begin{array}{c}-0.011 \\
(0.020)\end{array}$ & \\
\hline Log NA stability squared & & $\begin{array}{l}0.068^{*} \\
(0.036)\end{array}$ & $\begin{array}{l}0.067^{* * *} \\
(0.034)\end{array}$ \\
\hline Log NA agency squared & & $\begin{array}{c}0.017 \\
(0.023)\end{array}$ & \\
\hline Log NA turnover $\times$ staffing & & $\begin{array}{r}-0.078 \\
(0.113)\end{array}$ & \\
\hline Log NA stability $\times$ staffing & & $\begin{array}{r}-0.183 \\
(0.182)\end{array}$ & \\
\hline Log NA agency $\times$ staffing & & $\begin{array}{c}0.117 \\
(0.106)\end{array}$ & \\
\hline Log NA stability $\times$ turnover & & $\begin{array}{r}-0.015 \\
(0.035)\end{array}$ & \\
\hline Log NA agency $\times$ turnover & & $\begin{array}{l}0.048^{* * *} \\
(0.022)\end{array}$ & $\begin{array}{l}0.055^{* * * * *} \\
(0.020)\end{array}$ \\
\hline Log NA agency $\times$ stability & & $\begin{array}{l}0.008 \\
(0.036)\end{array}$ & \\
\hline Log LPN staffing squared & & $\begin{array}{r}-0.109 * \\
(0.058)\end{array}$ & \\
\hline Log LPN turnover squared & & $\begin{array}{r}-0.004 \\
(0.023)\end{array}$ & \\
\hline Log LPN stability squared & & $\begin{array}{c}0.073 \\
(0.097)\end{array}$ & \\
\hline Log LPN agency squared & & $\begin{array}{c}-0.025^{* * *} \\
(0.012)\end{array}$ & \\
\hline Log LPN turnover $\times$ staffing & & $\begin{array}{c}0.005 \\
(0.061)\end{array}$ & \\
\hline Log LPN stability $\times$ staffing & & $\begin{array}{r}-0.097 \\
(0.094)\end{array}$ & $\begin{array}{c}-0.191 * * \\
(0.085)\end{array}$ \\
\hline Log LPN agency $\times$ staffing & & $\begin{array}{c}0.041 \\
(0.035)\end{array}$ & \\
\hline Log LPN stability $\times$ turnover & & $\begin{array}{c}0.010 \\
(0.068)\end{array}$ & \\
\hline Log LPN agency $\times$ turnover & & $\begin{array}{r}-0.017 \\
(0.013)\end{array}$ & $\begin{array}{r}-0.020^{*} \\
(0.012)\end{array}$ \\
\hline
\end{tabular}


Table 4: Continued

\begin{tabular}{|c|c|c|c|}
\hline & $\begin{array}{l}\text { Main Effects } \\
\text { Only }\end{array}$ & $\begin{array}{l}\text { All Nonlinear } \\
\text { Terms and } \\
\text { Interactions }\end{array}$ & $\begin{array}{l}\text { Stepwise (Including } \\
\text { Nonlinear Terms } \\
\text { and Interactions) }\end{array}$ \\
\hline Log LPN agency $\times$ stability & & $\begin{array}{r}-0.019 \\
(0.034)\end{array}$ & \\
\hline Log RN staffing squared & & $\begin{array}{l}0.140^{*} \\
(0.080)\end{array}$ & \\
\hline Log RN turnover squared & & $\begin{array}{c}0.032 \\
(0.025)\end{array}$ & \\
\hline Log RN stability squared & & $\begin{array}{c}-0.093^{* * *} \\
(0.039)\end{array}$ & $\begin{array}{c}-0.076^{* * *} \\
(0.032)\end{array}$ \\
\hline Log $R N$ agency squared & & $\begin{array}{c}-0.029^{* * *} \\
(0.014)\end{array}$ & $\begin{array}{c}-0.027^{* * *} \\
(0.014)\end{array}$ \\
\hline Log RN turnover $\times$ staffing & & $\begin{array}{r}-0.008 \\
(0.055)\end{array}$ & \\
\hline Log RN stability $\times$ staffing & & $\begin{array}{l}0.105 \\
(0.073)\end{array}$ & \\
\hline Log RN agency $\times$ staffing & & $\begin{array}{l}0.017 \\
(0.024)\end{array}$ & \\
\hline Log RN stability $\times$ turnover & & $\begin{array}{r}-0.022 \\
(0.032)\end{array}$ & \\
\hline $\log \mathrm{RN}$ agency $\times$ turnover & & $\begin{array}{l}-0.065^{* * * *} \\
(0.017)\end{array}$ & $\begin{array}{l}-0.056^{* * * * *} \\
(0.014)\end{array}$ \\
\hline Log RN agency $\times$ stability & & $\begin{array}{r}-0.009 \\
(0.022)\end{array}$ & \\
\hline Constant & $\begin{array}{l}0.802^{* * * * *} \\
(0.189)\end{array}$ & $\begin{array}{l}0.899^{* * * *} \\
(0.209)\end{array}$ & $\begin{array}{l}0.773^{* * * *} \\
(0.195)\end{array}$ \\
\hline Adjusted $R^{2}$ & 0.33 & 0.38 & 0.37 \\
\hline
\end{tabular}

*Statistically significant at the .10 level or better;

**Statistically significant at the .05 level or better;

**** Statistically significant at the .01 level or better.

${ }^{\dagger}$ Higher values indicate better quality. Factor loadings were: $0.68,0.30,0.71,0.48,0.60,0.22,0.29$, $0.74,0.73,0.77$, and 0.63 , respectively for help with daily activities increased, with moderate to severe pain, high-risk residents with pressure sores, low-risk residents with pressure sores, physical restraint use, more depressed or anxious, low-risk residents with loss bladder or bowel control, had a catheter inserted and left in bladder, spend most time in bed or in a chair, ability to move in/ around room got worse, and with urinary tract infection.

$N=1,071$ facilities and 563 markets; standard error given in parentheses.

NA, Nurse Aide; RN, Registered Nurse; LPN, Licensed Practical Nurse; FTE, full-time-equivalent.

The coefficients from the regression examining the individual long-stay QMs are given in the online Appendix A, and the individual short-stay QMs in the online Appendix B. In many cases the results for the individual QMs are similar to those for the quality factor. For example, for staffing levels, we find 
Figure 2: Nurse Aide Turnover, Agency Use, and Overall Quality.

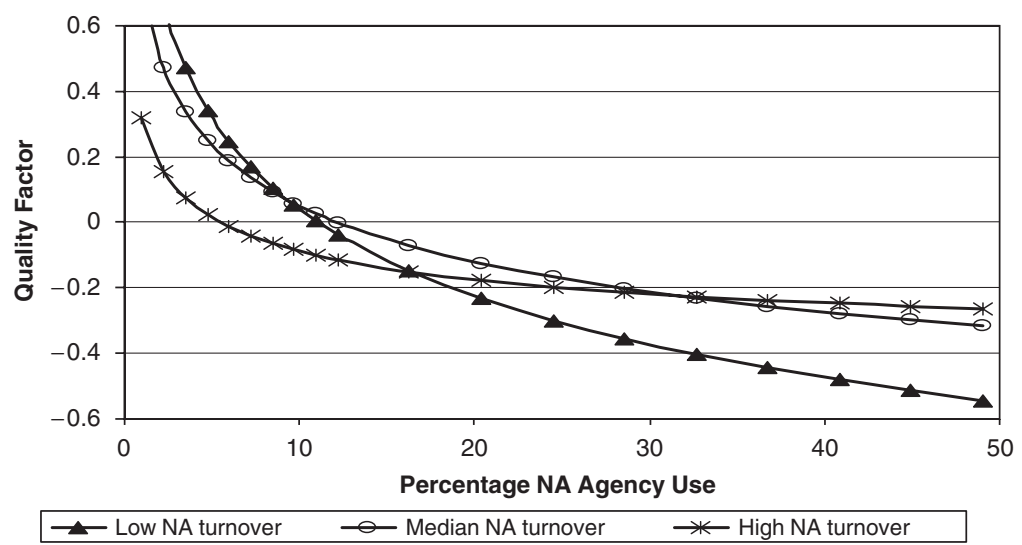

Note: High values on the Overall Quality axis reflect better quality. The figure shows that at low levels of NA turnover there is a stronger negative association between quality and NA agency use than at median or high levels of NA turnover. Low Nurse Aide turnover is defined as the 5th percentile (i.e.,0\%); Median Nurse Aide turnover is defined as the 50th percentile (i.e., 16\%); High Nurse Aide turnover is defined as the 95th percentile (i.e., 200\%); NA=Nurse Aide.

for many QMs (i.e., in six of the 11 long-stay QMs) that a greater number of RNs are associated with higher overall quality and NA staffing levels were in most cases not significant. For turnover, we find that high RN turnover is associated with higher overall quality for several QMs (i.e., in three of the 11 long-stay QMs and one of the three short-stay QMs), but the LPN and NA turnover variables are mostly not significant. For stability, we find that high rates of NA stability are generally associated with higher overall quality (i.e., in seven of the 11 long-stay QMs and one of the three short-stay QMs). For agency use, we find that high rates of $\mathrm{RN}$ agency use are associated with lower quality (i.e., in nine of the 11 long-stay QMs and two of the three short-stay QMs) and that high rates of NA agency use are associated with lower quality (i.e., in six of the 11 long-stay QMs and one of the three short-stay QMs).

\section{DISCUSSION}

Nursing home residents are characteristically frail and are highly dependent upon staff for their physical, mental, and social needs. In many cases this dependence can last for several years. The scope and duration of residents' dependence on staff likely predisposes them to a high degree of sensitivity to the composition of staff. We propose that an adverse staffing composition 
Figure 3: Registered Nurse Turnover, Agency Use, and Overall Quality.

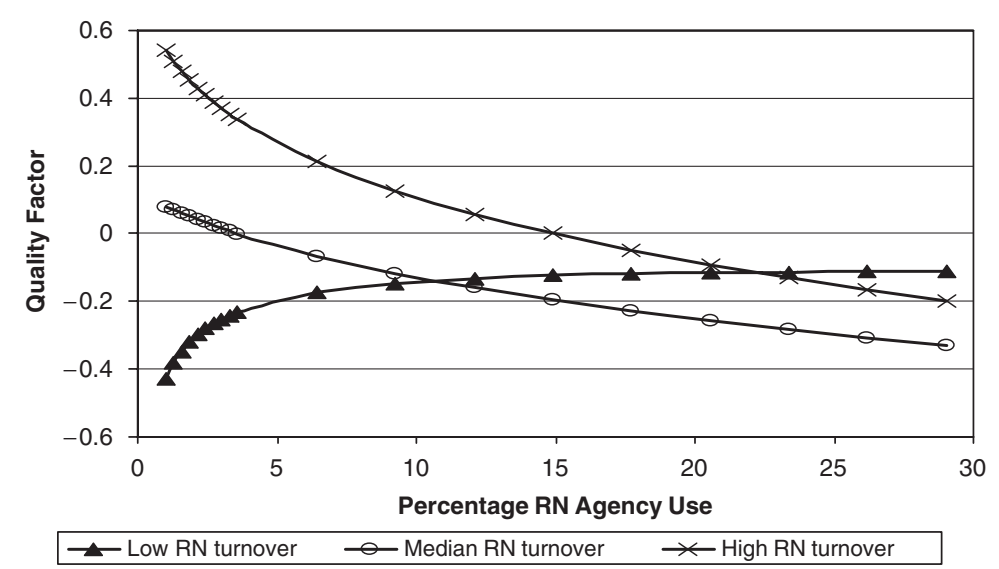

Note: High values on the Overall Quality axis reflect better quality. The figure shows that at high levels of RN turnover there is a negative association between RN agency use and quality, but not at low levels of RN turnover. Low RN turnover is defined as the 5 th percentile (i.e., $0 \%$ ); Median RN turnover is defined as the 50th percentile (i.e., 26\%); High RN turnover is defined as the 95th percentile (i.e., 122\%); RN =Registered Nurse.

comes from high turnover rates, low staffing levels, low stability levels, and high use of agency staff. To some degree quality of care would seem to be influenced by all of these staffing characteristics. However, the relationships are complex and differ by staff type (i.e., NA, LPN, or RN), are nonlinear, and include interactions. Thus, for our hypotheses overall we find mixed support.

Overall, we found most significant findings for agency use and stability. That is, following our hypotheses, high agency use and low stability are associated with lower quality. Our findings for staffing levels and turnover are not as robust. These overall results are of interest, because the literature to date has tended to focus upon staffing levels and turnover. Our results indicate that this emphasis may be misplaced, or at the very least staffing research should also include agency use and worker stability.

When we examine our findings based on staff type, we find most significant associations for RNs and NAs, and few for LPNs. For both RNs and NAs, following our hypothesis, high use of agency staff are associated with lower quality. For RNs, staffing levels are also important, with low staffing associated with lower quality; whereas, for NAs, stability is also important, with low stability associated with lower quality.

We also acknowledge that contrary findings exist for $\mathrm{RN}$ stability and $\mathrm{RN}$ turnover. That is, contrary to our hypotheses, low $\mathrm{RN}$ stability and high $\mathrm{RN}$ turnover are associated with higher quality. One possible explanation is 
that newer RNs bring expertize from their exposure to other advanced practice settings. On the other hand, it could be that facilities that provide highquality care are replacing RNs. As we discuss below, these results may also reflect uncertain causal direction. Disentangling these explanations will require new data collection. We should also note that other studies have identified counter intuitive findings when examining $\mathrm{RN}$ staffing in nursing homes (e.g., Schnelle et al. 2004). We clearly need more information on the impact of $\mathrm{RN}$ staffing characteristics in nursing homes.

Past research in this area has tended to focus on staffing levels (e.g., Harrington and Swan 2003). As stated previously, few studies have included multiple staffing characteristics, which likely makes these prior models underspecified. Our results show that staffing levels are important in nursing homes. However, we also show that turnover, staff stability, and agency use may also be influential influences on quality. This may be especially so for NAs. As we show in Figure 2, the highest quality can only be achieved when nursing homes have both a low percent of NA turnover and agency use is low.

We have seen several recent policy changes that have had a direct impact on nursing home staffing characteristics. Policy makers so far seem to have responded to the lower quality of nursing homes by suggesting (and in some states mandating) minimum staffing levels. Our results show that turnover, stability, and use of agency staff are also significant influences on quality. Policy makers may be hard pressed to regulate these staffing characteristics; nevertheless, several initiatives are currently ongoing, that are designed to improve the job satisfaction (and thereby higher stability and lower turnover) of staff. These include both the Better Jobs Better Care (BJBC) demonstrations (www.bjbc.org) and CMS demonstration grants (www.cms.hhs.gov/ newfreedom).

In addition, facilities may be using agency staff to meet minimum staffing level requirements. Given that our results show a negative association between agency use (i.e., for RNs and NAs) with quality of care, in some cases this could have the unintended effect of worsening quality. This negative association is even more severe if there is high turnover (as shown in Figure 2), which we speculate could occur if facilities also try to meet staffing requirements through less-selective hiring practices.

These staffing characteristics are all clearly influenced by individual facility/management decisions. However, the short- and long-term direct costs associated with various staffing choices are complex. For example, high turnover rates lead to expenditures associated with training and hiring, but more selective recruitment and hiring to reduce turnover also can be expensive. 
Likewise, agency staff often cost more per day than regular staff, but management avoids many administrative, training, and benefit costs and avoids a long-run commitment. In addition, indirect cost considerations include the impact of staffing characteristics on quality of care, and in turn this can reduce the demand from more profitable private-pay residents.

Our findings show that in some cases the gains in quality achieved by improving staffing characteristics can be considerable. For example, with a decrease in NA agency use from 39.1 percent (i.e., $1 \mathrm{SD}$ above the mean) to 20.2 percent (i.e., the mean), restraint use decreases from 15.5 to 13.4 percent (i.e., a decrease of $0.24 \mathrm{SD}$ ). It also is associated with more residents that have a decrease in mobility (from 8.0 to 9.7 percent, a decrease of $0.33 \mathrm{SD}$ ). Clearly, these kinds of changes in quality have some clinical relevance, especially when as in this case the quality gains occur across multiple and varied measures (see online Appendices A and B).

Given that in our analysis quality is dependent on three types of staff and four staff characteristics, making recommendations on what operational and policy approaches should be used with these 12 characteristics is difficult. We believe a simulation analysis that includes all of these factors, in addition to costs, would be an appropriate next analytic step capable of providing more specific recommendations.

We also found numerous organizational and market variables to be significant. This is in line with the theoretical model used to guide our selection of variables. Our results for the organizational characteristics seem particularly robust in showing for-profit facilities and high bed size are associated with low quality. This is consonant with several recent examinations examining organizational characteristics of nursing homes (e.g., Harrington and Swan 2003; Castle and Engberg 2005). In many cases higher levels of competition are also associated with lower quality. These results are also consonant with several recent examinations examining market characteristics of nursing homes (e.g., Grabowski 2001). Thus, our results provide some further evidence that nursing homes are sensitive to their organizational and market context.

\section{Limitations and Suggestions for Further Research}

The quality indicators used came from NHC. These measures represent a consensus on what constitutes quality in nursing homes. They also come from a known reliable data source, the MDS. Nevertheless, NHC quality indicators have limitations, most notable of which are numerous facilities with blank fields (GAO 2002). 
Because of concerns with staffing level data reported in the OSCAR, we instead used primary data collection to obtain staffing measures. Using pairedsample correlations, we compared these reported levels with the OSCAR data and found levels of correlation between them of approximately 0.72 , which does not meet the 0.80 minimum reliability standard.

Recent analyses have shown that the relative difference in reported turnover rates can differ by as much as 47 percent, depending on the definition of turnover used (Castle 2006). The definition of turnover (and 6-month time frame) we used was chosen because in this prior analysis it was shown to have less measurement error than other definitions (Castle 2006). Nevertheless, all turnover rates were self-reported by administrators, and as is often the case with self-reported measures, we were not able to determine the validity or reliability of the reported rates.

Concerns have been raised about the possible endogeneity of turnover and staffing (Harrington and Swan 2003). Quality, turnover, and staffing will all be endogenous variables if their values are determined jointly in the model. This can occur for two reasons. First, there could be omitted variables that affect all of these measures, leading them to be correlated even if there is no causal relationship among turnover, staffing, and quality. Second, causality might, at least in part, run in the other direction. For example, higher quality of care might make staff less likely to quit or might make it easier to recruit new staff. Identification and estimation of the impact of turnover, agency staff, stability, and staffing on quality in a simultaneous equations (or structural) model may thus be advantageous in future studies.

An alternative method to creating quality factors would be to use a latent variable approach. The latent variable method differs from the factor approach in that it estimates the underlying factor structure of the QMs at the same time that the relationship to the staffing characteristics is estimated, thereby using information about the relationship between the staffing characteristics and each quality measure to group the QMs into factors. The disadvantage of the latent variable method is that the estimated quality factor constructs are specific to the staffing context, rather than being identified solely from the correlation among the staffing characteristics and therefore applicable to any context.

Alternative model specifications were tested in preliminary analyses. Some changes in the results did occur, indicating further analyses in this area may be warranted. For example, alternative specifications in the type and number of interactions could be examined. We chose to include interactions among the staffing characteristics for each type of caregiver. Alternatively, it 
would be possible to examine interactions among the types of caregivers for each staffing characteristic. For example, it is possible that more use of agency RNs affects the association between NA agency use and quality. In fact, it is possible that there are interactions between one staffing characteristic for one caregiver type and a different staffing characteristic for a different caregiver type. Clearly, the possibilities are very numerous, and deserve attention in new data sets and new analyses.

With 1,071 nursing homes coming from six states our sample is relatively large. Moreover, many of the dependent and independent variables were similar to known national averages. Nevertheless, this was not the case for all variables. For example, fewer chain facilities than the national average were included in our data. Therefore, we also have to acknowledge that the generalizability of our findings may be limited.

\section{CONCLUSION}

We find that quality of care is associated with many of the staffing characteristics examined. In addition, the interactions clearly show that achieving higher quality is dependent upon more than having one favorable staffing characteristic alone. Our results show that staff characteristics such as turnover, staffing levels, worker stability, and agency staff should be addressed simultaneously to improve the quality of nursing homes. Moreover, our findings for agency use and stability were robust; thus, greater attention should be directed towards agency use and staff stability in nursing homes.

\section{ACKNOWLEDGMENT}

Funding for this work came from a grant from the National Institute on Aging (1 R01 AG027896-01).

Disclosures: The authors have no conflicts of interest.

Disclaimers: This work represents the opinions of the authors, and not necessarily those of our funder.

\section{REFERENCES}

Abt Associates. 2003. Validation of Long-Term and Post-Acute Quality Indicators. Cambridge, MA: Abt Associates Inc.

2004. National Nursing Home Quality Measures: User's Manual November 2004 (v1.2). Cambridge, MA: Abt Associates Inc. 
Barry, T., D. Brannon, and V. Mor. 2005. "Nurse Aide Empowerment Strategies and Staff Stability: Effects on Nursing Home Resident Outcomes." Gerontologist 45 (3): 309-17.

Bowers, B. J., S. Esmond, and N. Jacobson. 2000. "The Relationship between Staffing and Quality in Long-Term Care: Exploring the Views of Nurse Aides." Journal of Nursing Care Quality 14 (4): 55-64.

Castle, N. G. 2006. "Measuring Staff Turnover in Nursing Homes." Gerontologist 46 (2): 210-9.

Castle, N. G., and J. Engberg. 2005. "Staff Turnover and Quality of Care in Nursing Homes." Medical Care 43 (6): 616-26.

Center for Medicare and Medicaid Services. 2002 "Report to Congress: Appropriateness of Minimum Nurse Staffing Ratios in Nursing Homes Phase II Final Report." Department of Health and Human Services. Available at http:// cms.hhs.gov/medicaid/reports/rp1201home.asp

Decker, F. H., P. Gruhn, L. Matthews-Martin, K. J. Dollard, A. M. Tucker, and L. Bizette. 2003. Results of the 2002 AHCA Survey of Nursing Staff Vacancy and Turnover in Nursing Homes. Washington, DC: American Health Care Association; Health Services Research and Evaluation.

Deitzer, D., J. Wessell, K. Myles, and P. Trimble. 1992. "Agency Nurses: The Right Solution to Staffing Problems?" Journal of Long-Term Care Administration 20: 29-33.

General Accounting Office. 2002. Nursing Homes: Public Reporting of Quality Indicators Has Merit, but National Implementation Is Premature. Washington, DC: General Accounting Office.

Grabowski, D. C. 2001. "Medicaid Reimbursement and the Quality of Nursing Home Care." Journal of Health Economics 20: 549-69.

Harrington, C. 2005. "Nurse Staffing in Nursing Homes in the U.S." Journal of Gerontological Nursing 31 (2): 18-23.

Harrington, C., and J. H. Swan. 2003. "Nursing Home Staffing, Turnover, and Case Mix." Medical Care Research and Review 60 (3): 366-92.

Harrington, C., J. O’Meara, M. Kitchener, L. Simon, and J. F. Schnelle. 2003. "Designing a Report Card for Nursing Facilities: What Information Is Needed and Why." Gerontologist 43: 47-57.

Health Care Financing Administration. 2000. "Report to Congress: Appropriateness of Minimum Nurse Staffing Ratios in Nursing Homes." Department of Health and Human Services. Available at http://www.hcfa.gov/medicaid/reports/rp700exs.pdf

Institute of Medicine. 2001. Improving the Quality of Long-Term Care. Washington, DC: National Academy Press.

Knapp, M., and S. Missiakoulis. 1983. "Predicting Turnover Rates among the Staff of English and Welsh Old People's Homes." Social Science and Medicine 17: 29-36.

Konetzka, R. T., D. Yi, E. C. Norton, and K. E. Kilpatrick. 2004. "Effects of Medicare Payment Changes on Nursing Home Staffing and Deficiencies." Health Services Research 39: 463-88.

Louwe, H., and A. Kramer. 2002 "Report to Congress: Appropriateness of Minimum Nurse Staffing Ratios in Nursing Homes Phase II Final Report.” Department of 
Health and Human Services 2002. Available at http://cms.hhs.gov/medicaid/ reports/rp1201home.asp

Mueller, C., G. Arling, R. Kane, J. Bershadsky, D. Holland, and A. Joy. 2006. "Nursing Home Staffing Standards: Their Relationship to Nurse Staffing Levels." Gerontologist 46 (1): 74-80.

Needleman, J., P. I. Beurhaus, S. Mattke, M. Stewart, and K. Zelevinsky. 2001. "Nurse Staffing and Patient Outcomes in Hospital." Final Report to the United States Department of Health and Human Services. Contract No. 230-99-0021.

Schnelle, J. F., S. F. Simmons, C. Harrington, M. Cadogan, E. Garcia, and B. BatesJenson. 2004. "Relationship of Nursing Home Staffing to Quality of Care". Health Services Research 39 (2): 225-50.

Spector, W., and H. A. Takada. 1991. "Characteristics of Nursing Homes That Affect Resident Outcomes." Journal of Aging and Health 3: 427-54.

Staw, B. 1980. "The Consequences of Turnover." Journal of Occupational Behavior 1: 253-73.

Stone, R. I. 2004. "The Direct Care Worker: The Third Rail of Home Care Policy." Annual Review of Public Health 25: 521-37.

Straker, J. 1999. Reliability of OSCAR Occupancy, Census, and StaffData: A Comparison with the Ohio Department of Health Annual Survey of Long-Term Care Facilities. Oxford, $\mathrm{OH}$ : Technical Report Series 3-01; Scripps Gerontology Center.

Strzalka, A., and D. S. Havens. 1996. "Nursing Care Quality: Comparison of UnitHired, Hospital Float Pool, and Agency Nurses." Journal of Nursing Care Quality $10(4): 59-65$.

Williams, P. M., and J. A. Katz. 1999. "Derivation of New Measures for Retention." Paper presented at the National Conference of the U. S. Association for Small Business and Entrepreneurship.

\section{SUPPLEMENTARY MATERIAL}

The following supplementary material for this article is available:

Appendix A: Regression Analyses Examining Staffing Characteristics and Long-Stay Quality Measures.

Appendix B: Regression Analyses Examining Staffing Characteristics and Short-Stay Quality Measures.

This material is available as part of the online article from http://www. blackwellsynergy.com/doi/abs/10.1111/j.1475-6773.2007.00704.x (this link will take you to the article abstract).

Please note: Blackwell Publishing is not responsible for the content or functionality of any supplementary materials supplied by the authors. Any queries (other than missing material) should be directed to the corresponding author for the article. 